\title{
Vegetation Effects on Fish Distribution in Impounded Salt Marshes
}

\author{
Eric D. Stolen ${ }^{1,2,}$, Jaime A. Collazo ${ }^{3}$, and H. Franklin Percival ${ }^{4}$
}

\begin{abstract}
We compared the density and biomass of resident fish in vegetated and unvegetated flooded habitats of impounded salt marshes in the northern Indian River Lagoon (IRL) Estuary of east-central Florida. A $1-\mathrm{m}^{2}$ throw trap was used to sample fish in randomly located, paired sample plots ( $n=198$ pairs) over 5 seasons in 7 impoundments. We collected a total of 15 fish taxa, and $88 \%$ of the fishes we identified from the samples belonged to three species: Cyprinodon variegatus (Sheepshead Minnow), Gambusia holbrooki (Eastern Mosquitofish), and Poecilia latipinna (Sailfin Molly). Vegetated habitat usually had higher density and biomass of fish. Mean fish density (and 95\% confidence interval) for vegetated and unvegetated sites were $8.2(6.7-9.9)$ and $2.0(1.6-2.4)$ individuals $\mathrm{m}^{-2}$, respectively; mean biomass (and 95\% confidence interval) for vegetated and unvegetated sites were $3.0(2.5-3.7)$ and $1.1(0.9-1.4) \mathrm{g} \mathrm{m}^{-2}$, respectively. We confirmed previous findings that impounded salt marshes of the northern IRL Estuary produce a high standing stock of resident fishes. Seasonal patterns of abundance were consistent with fish moving between vegetated and unvegetated habitat as water levels changed in the estuary. Differences in density, mean size, and species composition of resident fishes between vegetated and unvegetated habitats have important implications for movement of biomass and nutrients out of salt marsh by piscivores (e.g., wading birds and fishes) via a trophic relay.
\end{abstract}

\section{Introduction}

Animals choose among alternative habitats based on a combination of factors including availability, rewards (food, favorable conditions for growth), and costs (predation, unfavorable conditions) associated with each habitat type. In salt marshes, resident fishes must often trade-off predation risk, food availability, and environmental conditions such as temperature, salinity, and dissolved oxygen when selecting habitat to maximize growth and survival (e.g., Halpin 2000, Rozas and Odum 1988). Predators such as wading birds may take advantage of these tradeoffs when they choose foraging sites (Frederick and Loftus 1993, Kersten et al. 1991). An ecological understanding of the factors governing distribution of fish in salt

${ }^{1}$ Department of Wildlife Ecology and Conservation, University of Florida, Gainesville, FL 32611-0430. ${ }^{2}$ Current address - Dynamac Corporation, Mail Code: DYN-2, Kennedy Space Center, FL 32899. ${ }^{3}$ US Geological Survey, North Carolina Cooperative Fish and Wildlife Research Unit, Department of Zoology, North Carolina State University, Raleigh, NC 27695-7617. ${ }^{4}$ US Geological Survey, Florida Cooperative Fish and Wildlife Research Unit, Department of Wildlife Ecology and Conservation, University of Florida, Gainesville, FL 32611-0485. * Corresponding author eric.d.stolen@nasa.gov. 
marsh habitat is important because of their role in contributing nutrients and biomass to the adjacent estuary via a trophic relay; the process by which mobile predators, such as fish and birds, move prey biomass across estuarine boundaries (Kneib 1997, Stevens et al. 2006).

Much of the coastal salt marsh habitat in the United States is intensively managed, and often this includes alteration of the hydrology of the marsh, a practice known as structural marsh management or impounding (Mitchell et al. 2006). Most of the salt marshes in the northern Indian River Lagoon (IRL) of east-central Florida were impounded for mosquito control from 1950-1970, often resulting in an increase in unvegetated open water habitat at the expense of vegetated habitat (Brockmeyer et al. 1997). Impounding resulted in a reduction of fish species (Gilmore et al. 1982, Harrington and Harrington 1982), but also an increase in standing stocks of resident marsh fishes (Stevens et al. 2006). Although efforts are underway to restore hydrologic connections between the estuary and salt marshes, further impacts are expected (Brockmeyer et al. 1997). Information on resident fish habitat preference will be useful in understanding the consequences of vegetation loss on marsh function; this may be increasingly important as coastal wetlands are inundated due to sea-level rise (Michener et al. 1997).

We conducted this study during a broader investigation of factors that influence wading-bird foraging success within impounded salt marsh habitat of the northern IRL (Stolen 2006). The primary objective was to compare the density, biomass, and mean length of resident fish between unvegetated and vegetated habitats within impounded salt marshes of the northern IRL. In this paper, we also report information on the seasonal patterns of fish abundance within this system.

\section{Field-site Description}

The study was conducted within 7 salt marsh impoundments located in the northern portion of the IRL, an estuary on the central east coast of Florida (Fig. 1). Historically, the eastern shore of the northern IRL was extensively vegetated with irregularly flooded salt marsh (Schmalzer 1995); however, most of this salt marsh was impounded for mosquito control by the 1970s (Brockmeyer et al. 1997). Habitat within impoundments is similar to native salt marsh and is predominantly a heterogeneous mixture of unvegetated open water and vegetated habitats, with tall marsh grass (e.g., Spartina bakeri Merr. [Sand Cordgrass]) and short marsh vegetation (e.g., Distichlis spicata L. [Seashore Saltgrass], Batis maritima L. [Saltwort]) predominating in vegetated areas (Schmalzer 1995). Due to the linear nature of the IRL, salt marshes in the study area are isolated from the nearest ocean inlet, and daily marsh water levels change $<1 \mathrm{~cm}$ (Smith 1987). In this region, seasonal and wind-driven water-level fluctuations are of much greater importance than lunar tides (Smith 1987; 1993). A high-water period occurs from September through November followed by a gradual decline in water level, with the lowest level 
occurring in early spring. These hydrological changes greatly influence water depth in salt marsh habitat connected to the estuary and control the extent of marsh flooding.

Initially, impounding northern IRL marshes reduced the diversity of fish using these habitats by severing the migratory corridors used by transient species (Gilmore et al. 1982, Harrington and Harrington 1982). Impounding these marshes also drastically altered their hydrology by increasing hydroperiods and water depths, reducing vegetated area, and concomitantly increasing the area of open water (Brockmeyer et al. 1997). These changes increased the populations of small resident fishes (e.g., Cyprinodon variegatus Lacepède (Sheepshead Minnow), Gambusia holbrooki Girard (Eastern Mosquitofish), and Poecilia latipinna Lesueur (Sailfin Molly); Gilmore et al. 1982) with measurable benefits to wading birds.

\section{Methods}

\section{Prey sampling}

Sampling was conducted quarterly from July 2001 through July 2002 in 7 impoundments containing salt marsh habitat along the estuarine edge (Fig. 1). Sampling was stratified across the following seasons to coincide with key periods of wading-bird activity in the northern IRL (Stolen 2006): summer (late June-September), fall (October-December), winter

Figure 1. Map of study site in the northern Indian River Lagoon estuary (which is made up of the Indian River, the Banana River, and the Mosquito Lagoon). Salt marsh impoundments are shown as hatched areas; study impoundments are highlighted in black.

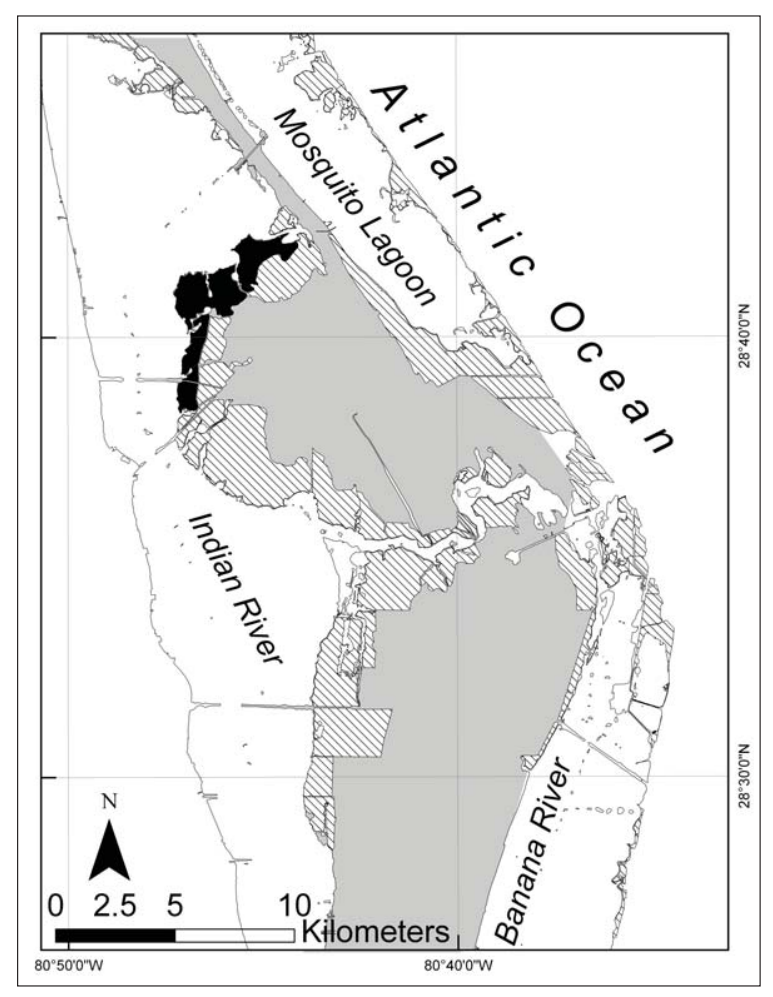


(January-March), and spring (April-early June). During each quarterly sampling period, we randomly selected 10-15 sampling locations within each impoundment using GIS, and identified these locations in the field using GPS. A $1-\mathrm{m}^{2}$ throw trap was used to sample fish at the nearest openwater habitat from each random location. Open water was defined as a flooded area with no emergent marsh vegetation that was at least $2 \mathrm{~m}$ in diameter. Once an open-water sample was collected, a paired sample location was selected within the nearest flooded vegetated habitat. Vegetated sites had to be at least $5 \mathrm{~m}$ from the open water sample site and within $1 \mathrm{~m}$ of the marsh-water interface. Vegetated habitat also was defined as a flooded area at least $2 \mathrm{~m}$ in diameter with at least $25 \%$ emergent vegetation cover. If no such habitat existed within $200 \mathrm{~m}$ of the open-water sample site, then no paired vegetated sample was collected. If no open water existed within $200 \mathrm{~m}$ of the chosen random location, then only the nearest vegetated habitat was sampled. Throw-trap sampling (Kushlan 1981) was used to quantify resident marsh fish abundance because this gear has been shown to produce accurate estimates of fish abundance (Chick et al. 1992, Jordan et al. 1997, Rozas and Minello 1997). Researchers approached the sample site slowly on foot and then tossed a $1-\mathrm{m}^{2}$ throw trap from a distance of 1-2 m. After the trap landed, its edges were quickly secured against the substrate. Fish were then scooped from the trap using a $40-$ by $30-\mathrm{cm}$ dip net with $2-\mathrm{mm}$ mesh. Vegetation within the trap was removed if it impeded movement of the dip net. When the large dip net was scooped three times without catching any fish, we used a $15-$ by $10-\mathrm{cm}$ dip net with $2-\mathrm{mm}$ mesh that was more effective in scraping along the edges and into the corners of the trap. The sample was completed when the smaller dip net was scooped three consecutive times without a capture. The first thirty individuals of each fish species captured in each throw-trap deployment were measured to the nearest $\mathrm{mm}$ standard length (tip of snout to base of tail). The mass of these fish was estimated using species-specific regression equations developed for fish captured in other impoundments in the northern IRL (Stevens 2002).

\section{Analysis}

Fish density for each throw-trap deployment (hereafter referred to as sample) was calculated as the number of individuals of all species removed from the $1-\mathrm{m}^{2}$ trap. Sample biomass was calculated as the sum of biomass for all fish in a sample. When the number of individuals within a species was greater than 30, the biomass for that species was estimated as the number of fish multiplied by the sample mean biomass for that species.

We used analysis of variance (ANOVA) to test hypotheses about relationships between fish density, biomass, or size and the factors season, habitat type, and impoundment. The ANOVA model we used for these analyses was chosen using information-theoretic model selection based on expected relative Kullback-Leibler information (Burnham and Anderson 2002). The selection was made from a set of models that included models with each factor alone, a model with all two-way interactions, models with each two-way 
interaction alone, and models with two-way interactions and the remaining factor as a main effect. We used $\ln$ (fish density +1 ), $\ln$ (biomass +1 ), or $\ln ($ mean length) as the response variable in the ANOVAs to meet model assumptions. In a few instances, vegetated habitat estimates were missing due to lack of flooded habitat to sample in some impoundments and seasons; to balance the sampling design for the ANOVA models, the data for impoundments T10K, T10C, T10D, and for Summer 2001 were not included in the analyses.

We examined correlations between fish density, biomass, and mean length to better understand the distribution of biomass and energy available for the trophic relay. Spearman's correlation coefficients $(\rho)$ were calculated between density and biomass within samples, and also between habitats using the paired samples. Correlations were also calculated between sample density and mean length, and between density and the mean biomass per individual fish in the sample. For these statistics, we calculated mean length and mean biomass of individual fish by sample using only the individuals measured within a sample. All statistics were calculated using $\mathrm{R}$ version 2.5 (R Development Team 2007).

\section{Results}

Fish were captured at 174 of 326 unvegetated sites and 180 of 203 vegetated sites (Table 1). A total of 15 fish taxa were identified, but over $88 \%$ belonged to only three species (Sheepshead Minnow, Eastern Mosquitofish, and Sailfin Molly). The same ANOVA model was selected for both density and biomass, and included two-way interactions between habitat and season and habitat and impoundment (Table 2; for model selection details see Stolen 2006). These interactions predict a different effect of habitat on fish abundance, depending on which season or impoundment is considered. The model predictions showed that mean fish density and mean biomass were higher in vegetated than unvegetated habitat in summer and fall, but were more similar in winter and spring (Fig. 2). This pattern was less clear for impoundment T10L than the others.

Within samples, fish density and biomass were highly correlated for both unvegetated habitat (Spearman's $\rho=0.963, n=326, P<0.0001$ ) and vegetated habitat (Spearman's $\rho=0.852, n=203, P<0.0001$ ). The correlation between fish densities in vegetated versus unvegetated paired-samples was positive but weak (Spearman's $\rho=0.300, n=$ $198, P<0.0001$ ) as was that for biomass (Spearman's $\rho=0.190, n=198$, $P<0.007)$. The frequency distribution of fish density for unvegetated samples was highly skewed due to a large number of zeros ( $47 \%$ of unvegetated samples, $19 \%$ of vegetated samples; for details see Stolen 2006). Unvegetated sites were more likely to have no fish than vegetated sites $\left(\chi_{1}^{2}=44.76, P<0.001\right)$. Mean fish density for vegetated and unvegetated sites were 8.2 (95\% confidence interval 6.7-9.9) and $2.0(1.6-2.4)$ individuals $\mathrm{m}^{-2}$, respectively; mean biomass for vegetated and unvegetated sites were $3.0(2.5-3.7)$ and $1.1(0.9-1.4) \mathrm{g} \mathrm{m}^{-2}$, respectively. 


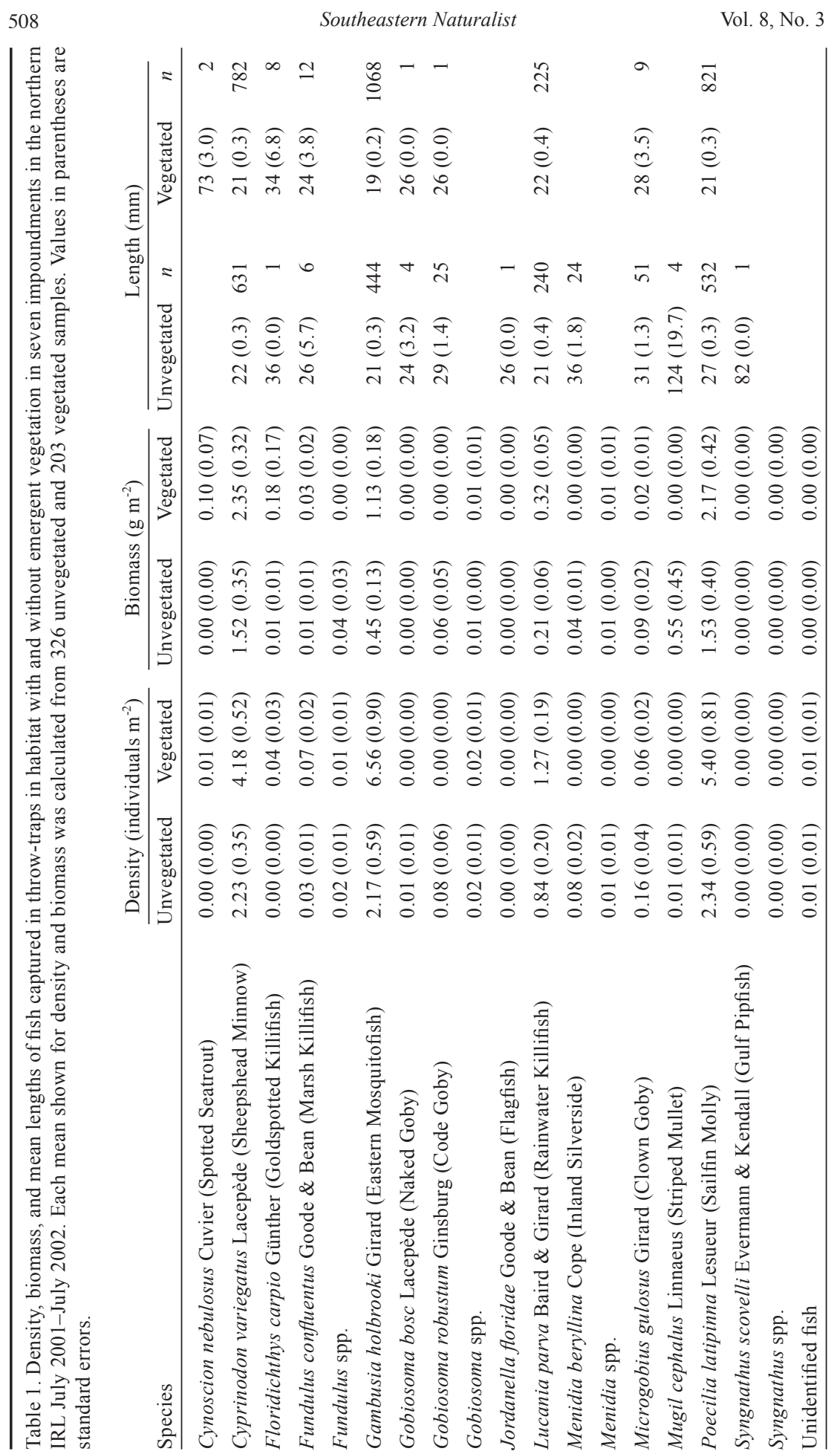


For consistency, we present a comparison of mean fish length between vegetated and unvegetated habitat using the same ANOVA model that was selected for fish abundance (Table 2). Fish were longer in unvegetated than vegetated sites in all seasons except in impoundment $\mathrm{T} 10 \mathrm{H}$, and the most pronounced differences occurred in winter (Fig. 2). Overall, mean fish length (by sample sites) was greater at unvegetated sites $(24.0 \mathrm{~mm}, 95 \%$ confidence interval $22.5-25.5, n=170)$ than at vegetated sites $(21.3 \mathrm{~mm}, 20.1-22.5, n=$ 179), and this difference was significant (unpaired $t$-test with unequal variances: $t=2.74, \mathrm{df}=331.6, P=0.007)$. Similarly, the mean biomass per fish was greater at unvegetated sites $(0.68 \mathrm{~g}, 95 \%$ confidence interval $0.47-0.89)$ than that at vegetated sites ( $0.52 \mathrm{~g}, 95 \%$ confidence interval $0.33-.72)$, but the difference was not significant (unpaired $t$-test with unequal variances: $t=1.90, \mathrm{df}=334.6, P=0.058)$. There was no correlation between the mean length and density of fish (Spearman's $\rho=0-0.035, P=0.519, n=349$ ), nor between the mean biomass and fish density (Spearman's $\rho=0-0.061, P=$ $0.257, n=349)$ at sample sites. The pattern of greater mean length in unvegetated sites held for three of the four most abundant species (Fig. 3).

\section{Discussion}

The high density and biomass of fish we measured within impounded salt marsh habitats in our study were similar to other studies of northern IRL impounded salt marsh systems (Schooley 1980, Stevens 2002) and

\begin{tabular}{|c|c|c|c|c|c|}
\hline Source of variation & Df & SS & MSE & $F$ & $\operatorname{Pr}(>F)$ \\
\hline \multicolumn{6}{|l|}{ Density } \\
\hline Impoundment & 3 & 95.91 & 31.97 & 27.88 & 0.00 \\
\hline Season & 3 & 5.39 & 1.80 & 1.57 & 0.20 \\
\hline Habitat & 1 & 60.23 & 60.23 & 52.52 & 0.00 \\
\hline Impoundment $\mathrm{x}$ habitat & 3 & 43.19 & 14.40 & 12.55 & 0.00 \\
\hline Season $\mathrm{x}$ habitat & 3 & 32.89 & 10.96 & 9.56 & 0.00 \\
\hline Residuals & 264 & 302.73 & 1.15 & & \\
\hline \multicolumn{6}{|l|}{ Biomass } \\
\hline Impoundment & 3 & 53.20 & 17.73 & 18.10 & 0.00 \\
\hline Season & 3 & 4.46 & 1.49 & 1.52 & 0.21 \\
\hline Habitat & 1 & 14.49 & 14.49 & 14.79 & 0.00 \\
\hline Impoundment $\mathrm{x}$ habitat & 3 & 39.36 & 13.12 & 13.39 & 0.00 \\
\hline Season $\mathrm{x}$ habitat & 3 & 21.21 & 7.07 & 7.22 & 0.00 \\
\hline Residuals & 264 & 258.60 & 0.98 & & \\
\hline \multicolumn{6}{|l|}{ Length } \\
\hline Impoundment & 3 & 0.87 & 0.29 & 3.78 & 0.01 \\
\hline Season & 3 & 1.34 & 0.45 & 5.81 & 0.00 \\
\hline Habitat & 1 & 0.91 & 0.91 & 11.81 & 0.00 \\
\hline Impoundment $\mathrm{x}$ habitat & 3 & 0.44 & 0.15 & 1.90 & 0.13 \\
\hline Season $\mathrm{x}$ habitat & 3 & 0.31 & 0.10 & 1.35 & 0.26 \\
\hline Residuals & 210 & 16.17 & 0.08 & & \\
\hline
\end{tabular}


indicate the potential of these systems to produce large amounts of biomass for transfer to the adjacent estuary by mobile predators (e.g., wading birds, fish). Perimeter dikes of impounded marshes may contribute to the production of large standing stocks of resident fish in two ways. First, these dikes dampen the effects of hydrologic changes, making water level in impoundments more stable and often deeper than in the adjacent estuary. This increased flooding results in more available habitat for fish, thus allowing diked wetlands to support larger populations of small marsh-resident fishes (e.g., Sheepshead Minnow, Eastern Mosquitofish, and Sailfin Molly) than shorter-hydroperiod, unimpounded marshes (Loftus and Eklund 1994, Trexler et al. 2002). Second, the perimeter dikes serve as a partial barrier to predatory fish, potentially lessening the impact of these predators on resident fish populations and thus increasing the standing stocks of small fish within impoundments (Stevens 2002). This abundance of prey is thought to at least partly explain why impounded wetland habitat in the northern IRL is attractive to foraging wading birds (Breininger and Smith 1990, Schikorr and Swain 1995, Smith and Breininger 1995, Stolen et al. 2002)

In this study, vegetated habitats usually had higher density and biomass of resident fish than did unvegetated sites. Similar patterns have been noted

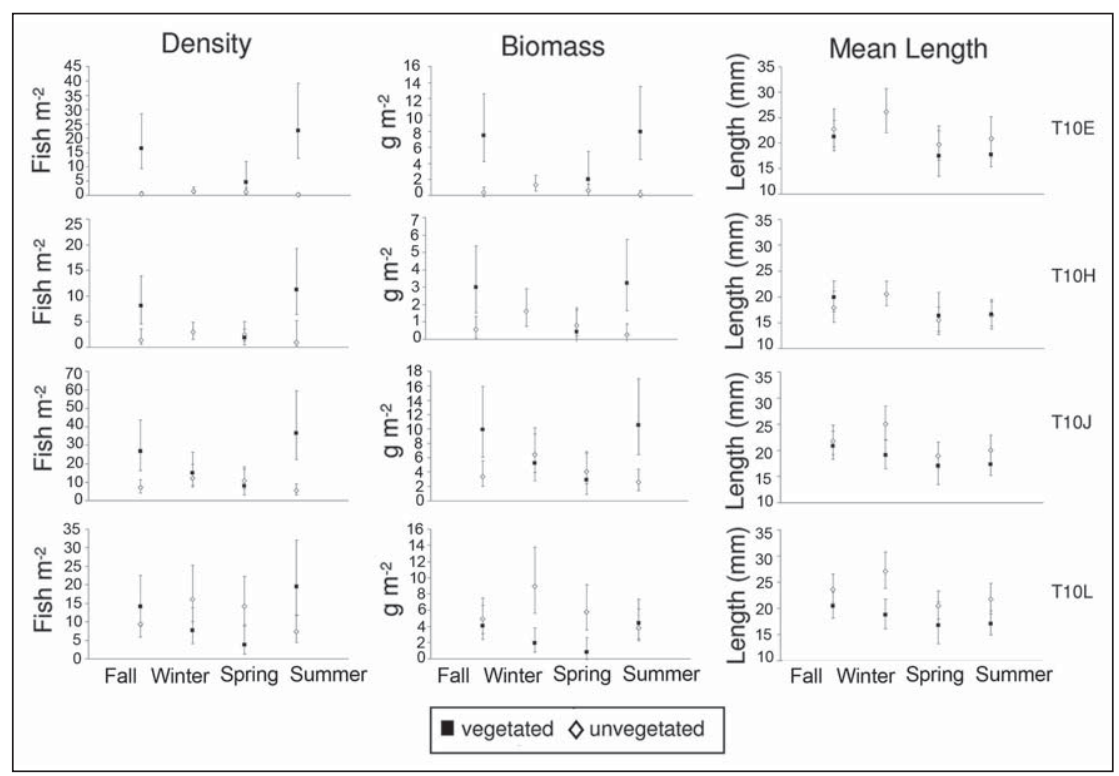

Figure 2. Predictions (back-transformed means and 95\% confidence intervals) from ANOVA models of fish abundance measures (density and biomass) and mean fish length for 4 impoundments (T10E, T10H, T10J, T10L) over 4 seasons. A few vegetated habitat estimates are missing due to a lack of available flooded habitat for sampling in some impoundments and seasons. Models were: $\ln ($ density +1$)=$ Impoundment + Season + Habitat + Impoundment*Habitat + Season*Habitat $\left(R^{2}=\right.$ $0.44) ; \ln ($ biomass +1$)=$ Impoundment + Season + Habitat + Impoundment*Habitat + Season*Habitat $\left(R^{2}=0.34\right)$; and $\ln ($ length $)=$ Impoundment + Season + Habitat + Impoundment*Habitat + Season*Habitat $\left(R^{2}=0.19\right)$. 
in other shallow systems containing mixtures of both habitat types, perhaps reflecting a trade-off in predation risk and food availability (Rozas and Odum 1988). The high relative use of vegetated over unvegetated habitat indicates that vegetated habitat is important for resident salt marsh fish in this region. In summer and fall seasons (June-December), vegetated habitat had higher fish abundance (density and biomass) than did unvegetated habitat, but fish abundance in the two habitats was much more similar in winter and spring (January-May). This seasonal change may occur as marsh resident fish move into deeper unvegetated sites as water levels fall and vegetated wetlands drain during late winter and spring. Later, the fish move back into the vegetated habitats when marshes are re-flooded in summer. Stevens (2002) demonstrated that marsh resident fishes (e.g., Sheepshead Minnow, Eastern Mosquitofish, and Sailfin Molly) in another impoundment in the northern IRL moved from the estuary edge to the marsh surface as rising water levels flooded these areas in late summer.

While density and distribution of prey are obviously important factors determining piscivore foraging success, others factors such as prey size also contribute to the suitability of foraging habitat (Trexler et al. 1994). An interesting finding of our study is that while prey density was usually higher in vegetated sites, unvegetated sites usually had larger prey. This could have

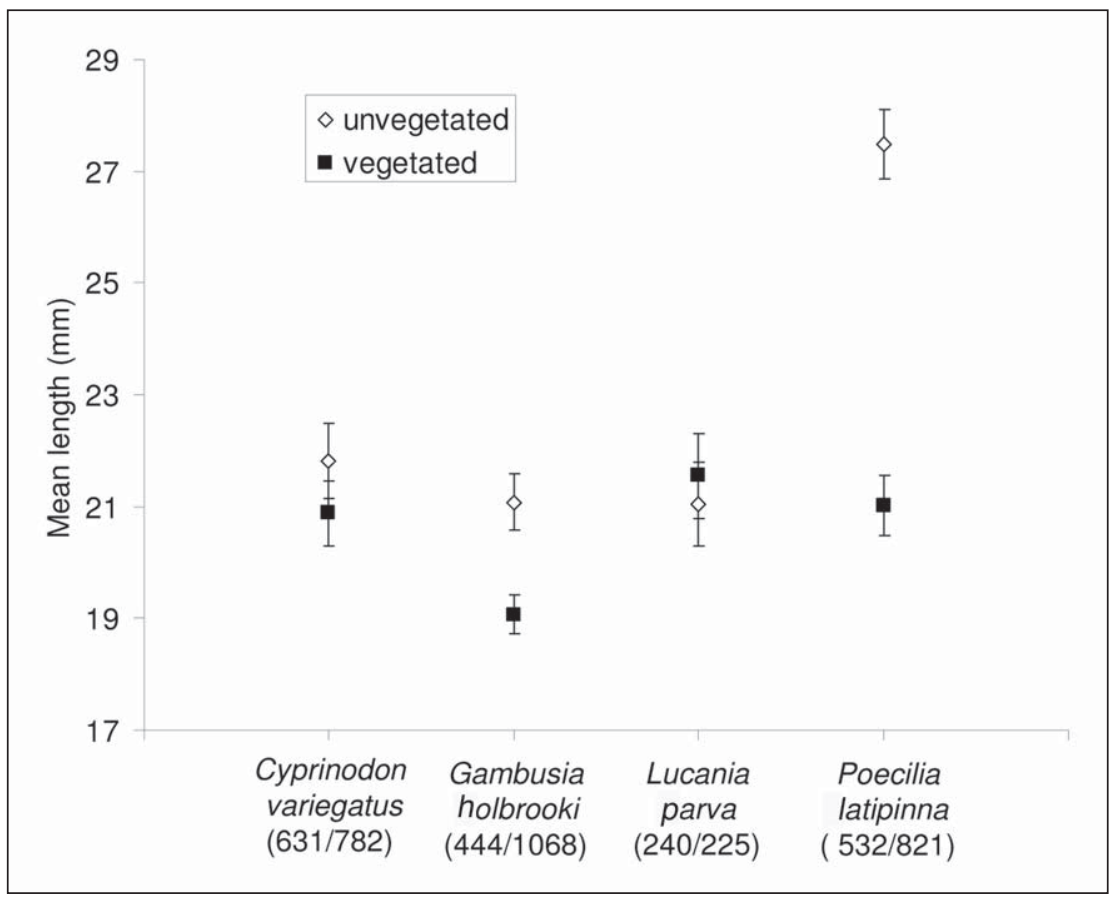

Figure 3. Comparison of fish size by habitat type. Mean lengths and $95 \%$ confidence intervals are given for the four most abundant species collected. Sample size for each estimate is given in parentheses (unvegetated/vegetated). 
implications for piscivores, since larger prey represent more concentrated energy and thus may be preferred prey. Such patterns can influence the ability of mobile predators to locate and capture prey, which in turn can affect their contribution to the trophic-relay. For example, recent work has demonstrated the connection between prey distribution and wading-bird foraging success (Kersten et al. 1991, Master et al. 2005), highlighting the importance of understanding factors influencing their prey availability within wetlands (e.g., Gawlik 2002, Stolen 2006). Previous studies have shown that wading birds foraging within impounded marsh in the northern IRL prefer unvegetated to vegetated flooded habitat for foraging (Breininger and Smith 1990; Smith and Breininger 1995). Stolen (2006) showed that wading-bird foraging-habitat preference was determined by habitat structure and spatial arrangement in addition to prey density. We plan to address this topic in more detail in a separate paper.

Coastal wetlands in many areas of the southeastern United States continue to experience loss of vegetated habitat due to structural marsh management (Mitchell et al. 2006). In the future, sea-level rise and increase in hurricane activity may also result in loss of vegetated salt marsh habitat (Michener et al. 1997). Multiple factors should be considered by managers when deciding how to respond to these changes in coastal wetlands. For example, although some species of waterbirds seem to prefer unvegetated habitats, loss of vegetated habitat may result in lower production of fish. Patterns of prey distribution in impounded salt marshes have important implications for piscivore habitat use within this system and highlight the importance of habitat diversity within the marsh system.

\section{Acknowledgments}

Dr. W. Knott III (retired), Chief of the Biological Sciences Branch, B. Summerfield, Chief of Center Operations, and K. Gorman at the Kennedy Space Center, FL, provided support during all phases of this study. G. Carter, P. Frederick, W. Kitchens, L Rozas, C. Montague, E. Reyier, P. Stevens, and two anonymous reviewers provided helpful suggestions that greatly improved the manuscript. We acknowledge the staff of the Merritt Island National Wildlife Refuge for granting permission to conduct this work on the refuge. This study was conducted under NASA contract NAS10-02001. This is contribution 7 from the Wetlands Initiative at Merritt Island National Wildlife Refuge.

\section{Literature Cited}

Breininger, D.R., and R.B. Smith. 1990. Waterbird use of coastal impoundments and management implications in east-central Florida. Wetlands 10:223-241.

Brockmeyer, R.E., J.R. Rey, R.W. Virnstein, R.G. Gilmore, and L. Earnest. 1997. Rehabilitation of impounded estuarine wetlands by hydrologic reconnection to the Indian River Lagoon, Florida (USA). Wetlands Ecology and Management 4:93-109.

Burnham, K.P., and D.R. Anderson. 2002. Model Selection and Multi-model Inference: A Practical Information-theoretic Approach. 2nd edition. Springer, New York, NY. 488 pp. 
Chick, J.H., F. Jordan, J.P. Smith, and C.C. McIvor. 1992. A comparison of 4 enclosure traps and methods used to sample fishes in aquatic macrophytes. Journal of Freshwater Ecology 7:353-361.

Frederick, P.C. and W.F. Loftus, 1993. Responses of marsh fishes and breeding wading birds to low temperatures: A possible behavioral link between predator and prey. Estuaries 16:216-222.

Gawlik, D.E. 2002. The effects of prey availability on the numerical response of wading birds. Ecological Monographs 72:329-346.

Gilmore, R.G., D.W. Cooke, and C.J. Donohoe. 1982. A comparison of the fish populations and the habitat in open and closed salt marsh impoundments in eastcentral Florida. Northeast Gulf Science 5:25-37.

Halpin, P.M. 2000. Habitat use by an intertidal salt-marsh fish: Trade-offs between predation and growth. Marine Ecology-Progress Series 198:203-214.

Harrington, R.W., Jr., and E.S. Harrington. 1982. Effects on fishes and their forage organisms of impounding a Florida salt marsh to prevent breeding by salt marsh mosquitoes. Bulletin of Marine Science 32:523-531.

Jordan, F., S. Coyne, and J.C. Trexler. 1997. Sampling fishes in vegetated habitats: Effects of habitat structure on sampling characteristics of the $1-\mathrm{m}^{2}$ throw trap. Transactions of the American Fisheries Society 126:1012-1020.

Kersten, M., R.H. Britton, P.J. Dugan, and H. Hafner. 1991. Flock feeding and food intake in Little Egrets: The effects of prey distribution and behavior. Journal of Animal Ecology 60:241-252.

Kneib, R.T. 1997. The role of tidal marshes in the ecology of estuarine nekton. Oceanography and Marine Biology: An Annual Review 1997 35:163-220.

Kushlan, J.A. 1981. Sampling characteristics of enclosure fish traps. Transactions of the American Fisheries Society 110:557-562.

Loftus, W.F., and A. Eklund. 1994. Long-term dynamics of an Everglades small-fish assemblage. Pp. 461-483, In S.M. Davis, and J.C. Ogden (Eds.). Everglades: The Ecosystem and Its Restoration. St. Lucie Press, Delray Beach, FL.

Master, T.L., J.K. Leiser, K.A. Bennett, J.K. Bretsch, and H.J. Wolfe. 2005. Patch selection by Snowy Egrets. Waterbirds 28:220-224.

Michener, W.K., et al. 1997. Climate change, hurricanes and tropical storms, and rising sea level in coastal wetlands. Ecological Applications 7:770-801.

Mitchell, L.R., S.W. Gabrey, P.P. Marra, and M. Erwin. 2006. Impacts of marsh management on coastal-marsh bird habitats. Pp. 155-175, In R. Greenberg, J.E. Maldonado, S. Droege, and M.V. McDonald (Eds.). Terrestrial Vertebrates of Tidal Marshes: Evolution, Ecology, and Conservation. Studies in Avian Biology No. 32.

R Development Core Team. 2007. R: A language and environment for statistical computing. R Foundation for Statistical Computing, Vienna, Austria. ISBN 3-900051-07-0. Available online at http://www.R-project.org.

Rozas, L.P., and T.J. Minello. 1997. Estimating densities of small fishes and decopod crustaceans in shallow estuarine habitats: A review of sampling design with focus on gear selection. Estuaries 20:199-213.

Rozas, L.P., and W.E. Odum. 1988. Occupation of submerged aquatic vegetation by fishes: Testing the roles of food and refuge. Oecologia 77:101-106.

Schikorr, K.E., and H.M. Swain. 1995. Wading birds: Barometer of management strategies in the Indian River Lagoon. Bulletin of Marine Science 57:215-229. 
Schmalzer, P.A. 1995. Biodiversity of saline and brackish marshes of the Indian River Lagoon: Historic and current patterns. Bulletin of Marine Science 57:37-48.

Schooly, J.K. 1980. The structure and function of warm-temperate estuarine fish communities. M.Sc. Thesis. University of Florida, Gainesville, FL. 107 pp..

Smith, N.P. 1987. Introduction to the tides of Florida's Indian River Lagoon. I. Water levels. Florida Scientist 50:49-61.

Smith, N.P. 1993. Tidal and wind-driven transport between Indian River and Mosquito Lagoon, Florida. Florida Scientist 56:235-246.

Smith, R.B., and D.R. Breininger. 1995. Wading-bird populations of the Kennedy Space Center. Bulletin of Marine Science 57:230-236.

Stevens, P.W. 2002. Test of salt marsh as a site of production and export of fish biomass with implications for impoundment management and restoration. Ph.D Dissertation. University of Florida, Gainesville, FL 195 pp.

Stevens, P.W., C.L. Montague, and K.J. Sulak. 2006. Fate of fish production in a seasonally flooded saltmarsh. Marine Ecology Progress Series 327:267-277.

Stolen, E.D. 2006. Habitat selection and foraging success of wading birds in impounded wetlands in Florida. Ph.D Dissertation. University of Florida, Gainesville, FL. 175 pp.

Stolen, E.D., Smith, R.B., and D.R. Breininger. 2002. Analysis of wading-bird use of impounded wetland habitat on Kennedy Space Center/Merritt Island National Wildlife Refuge 1987-1997. Report NASA Technical Memorandum 211173. Kennedy Space Center, FL. 70 pp.

Trexler, J.C., R.C. Tempe, and J. Travis. 1994. Size-selective predation of Sailfin Mollies by 2 species of heron. Oikos 69:250-258.

Trexler, J.C., W.F. Loftus, F. Jordan, J.H. Chick, K.L. Kandl, T.C. McElroy, and O.L. Bass, Jr. 2002. Ecological scale and its implications for freshwater fishes in the Florida Everglades. Pp. 153-181, In J.W. Porter, and K.G. Porter (Eds.). The Everglades, Florida Bay, and Coral Reefs of the Florida Keys: An Ecosystem Sourcebook. CRC Press, Boca Raton, FL. 